\title{
Micro-Design Intervention as a Method for Social Acupuncture to Stimulate Environmental Design Consciousness in Bulgaria
}

\author{
Milena Metalkova-Markova* \\ Faculty of Architecture, University of Architecture, Civil Engineering and Geodesy, Republic of Bulgaria
}

\begin{abstract}
Citation: Metalkova-Markova M. Micro-Design Intervention as a Method for Social Acupuncture to Stimulate Environmental Design Consciousness in Bulgaria. SEE J Archit Des. 2016 Ja 10; 2016:10016. http://dx.doi.org/ 10.3889/seejad.2016.10016 Key words: micro-design intervention; milieau; eco-museum environmental consciousness.

Correspondence: PhD Assoc. Prof. Milena MetalkovaMarkova Faculty Smirnenski No.1, 1046 Sofia, Republic of Bulgaria. E-mail metalkova_far@uacg.bg

Received: 27-Nov-2015; Revised: 31-Dec-2015; Accepted: 05-Jan-2016; Published: 10-Jan-2016

Copyright: ๑ 2016 Milena Metalkova-Markova. This is an open-access article distributed under the terms of the Creative distribution, and reproduction in any medium, provided the distribution, and reproduction in any
original author and source are credited.

Competing Interests: The author have declared that no competing interests exist.
\end{abstract}

Abstract

AIM: This paper aims to establish a method for a micro-design intervention as a social acupuncture used to stimulate sustainable development consciousness among young students during fieldwork in mountain and rural areas of Bulgaria.

MATERIAL AND METHODS: A theoretical framework of a sustainable approach for a microdesign intervention is established on the base of the phenomenological approach of Yuhani Pallasmaa, the concept of eco-museum type of endogeneous rural development by Toshio Mitsuhashi and the design philosophy of "Rural Studio" in USA. At the Department of History and Theory of Architecture at the Faculty of Architecture there are annual summer fieldworks for students of architecture usually organized at various mountain or rural villages within the country. Students are asked to conduct research on vernacular architecture, community relationships and local cultural milieau as part of their education curricula during the second year of their studies and in the $5^{\text {th }}$ year as a pre-diploma architectural practice. By means of micro-design interventions at focal public points or buildings students tried to find a way to activate people environmental consciousness and attitudes to their immediate environment. The main aim of the fieldworks was to connect research with a Design \& Make approach in order to catalyze citizen participation in a fusion with an environmental education.

RESULTS: These practical experiences seek to transform the research theory of sustainable environmental design into a pragmatic strategy to strengthen environmental consciousness for young generations of students in architecture in Bulgaria. Working and living together in rural or mountain traditional environments, trying to understand and assist local people by creating micro-design interventions is one of the best ways to heighten environmental design consciousness by an immersion in the milieau of local culture and community relationships.

CONCLUSION: A socially sustainable micro-design intervention as a strategy is only possible by combining the tools of an anthropologist and a designer or in other words by finding the intersection and cross-fertilization points between the cultural values of insiders and observers.

\section{Introduction}

Environmental design as an independent topic in architecture became very popular in Bulgaria since 1990's after the collapse of socialist state system. During the socialist period between 19451989 preservation of architectural heritage as a well defined realm fueled any effort to raise a consciousness about architecture and settlements as part of broader natural and socio-cultural contexts. The National Institute of Cultural Property has launched a large scale study of the vernacular architecture all over the country and some architecturally remarkable villages such as Jeravna, Brashlyan, Kovachevitza, etc. were designated as architectural reserves whose individual buildings, street silhouettes and overall settlement townscape had to be maintained in their authentic outlook since late 19th century. Surveys of the majority of settlements' buildings were executed and reconstructions of private houses in fragile conditions were undertaken by a craftsmen team of The National Institute of Cultural Property. Such reconstructions strictly adhered to a faithful preservation of exterior volumes and facades while some limited changes 
were allowed in the interior of the vernacular houses. As a result some interesting villages in Bulgarian countryside were homogeneously reconstructed and maintained as vernacular settlements in a unified townscape manner which even nowadays strike visitors with a "time travel" like experience bringing them back a few centuries ago into the Ottoman period town and lifestyle built up framework.

However as uniform reconstructions were executed by National Institute employees at a national scale the results often lack attention to detail, good quality and precision of the work, thus resulting in the later consequence that many private owners had to replace once again the "renovated" flooring or interior elements by themselves. Often authentic wooden structures for socially significant buildings were replaced by a hybrid structure with concrete slabs and brick walls, so emphasis was given to preserve the exterior silhouette as a part of an architectural ensemble rather than the structural authenticity of the building and the careful balance of materials related to its environmental functioning.

An emerging focus on the environmental design of the house as a well functioning man-made eco-system within an urbanized system was activated during the wide spread of the term and thinking about sustainable development and its related terms of energy-efficient architecture, ecological footprint of buildings and habitat protection in 1990's. Preservation of cultural heritage enlarged its meaning and significance to include protection of regional identity and the rich local palette of lifestyles and building traditions. On the other hand Bulgarian architectural education added subjects such as energy-efficient architecture, energy-efficient behavior of buildings, politics to maintain the environment and sustainable development within its academic curricula as demonstration of the shift of architectural paradigm toward addressing a more global consciousness and environmental responsibility.

\section{Micro-design intervention theoretical background}

Trying to define the mission of architects and educators related to local vernacular traditions I was influenced by the research of Toshio Mitsuhashi [1] at Kyoto Prefectural University in Japan. He was bringing students to villages in Tango peninsula on the northern side of Kyoto prefecture where they were involved in research of local vernacular housing traditions, local crafts and food habits. He was stressing the value of "Design of life" which I understood as to have a holistic understanding of regional culture and people indigenous lifestyles. The concept of endogeneous development as opposed to the standard model of top-down regional development implies working within local community and its value scales or mental systems where researchers and residents work together toward establishing future plans to empower and strengthen communal bonds or self-esteem within settlements. Toshio Mitsuhashi was bringing students to live among local people in Tango peninsula asking them to re-discover interesting for them aspects in various spheres within local lifestyledesign of baskets to collect fruits, design of boats and fishing equipment, minka folk house architecture, etc. Thus his aim was to revitalize local people selfesteem with the help of young students' energy and excitement with regional features which were common sense for the local residents, but contained aesthetic values appreciated by students. It was expected that the sharing between both groups' different viewpoints and perspectives on the potential of Tango regional culture could be the key to bring a new consciousness how to utilize this potential for the benefits of local community.

The concept of subsistence as the minimal necessary amount of food and shelter required to maintain human existence was very important element of endogeneous development of Tango region not only in relation to global sustainable development, but also as being an inherent characteristic of Japanese rural culture. Being restricted to live in a country with scarce natural resources Japanese culture in its essence contains admiration of refined simplicity, spatial/temporal restriction and minimalistic expression means. Habits of recycling and reuse combined with a deep sense of ritual purity are quintessentially rooted within Japanese lifestyle and Shinto cosmology.

The philosopher from Kyoto school Tetsuro Watsuji [2] developed the concept of fudo translated into English as climate and culture. According to Watsuji humans and environment continuously influence each other allowing for the continued evolution of both. Climate is the complex interconnected texture of influences that together weave an entire palette of people's attitudes and values. Therefore spatial climatic features leave a fundamental imprint on our cultural perceptions. From here we can conclude that in order to grasp the essence of certain culture it is necessary to have a personal experience of its spatial climatic features the term seasonal feelings provoked by natural changes is often stated to be fundamental to understand Japanese culture.

The well known French geographer Augustine Berque studied Watsuji and related the Japanese fudo with the French human milieau as the subjectively perceived and lived reality to be differentiated from the scientifically objectified environment [3]. Berque proposes to translate fûdo as médiance, meaning something that simultaneously mediates and is in the 
middle of the relation between a society and its environment.

The importance of this research is the attempt to define a human-centered ecological relationship to the environment which might be useful to reconsider once again at the time of various levels of global crises caused by a mechanistic view of the world, detaching or alienating humans from nature.

An application of such an ecological relationship to the environment is the idea of an Eco museum as a defined territory where the focus is placed on the identity of place where local community and its lifestyle are "exposed" to outsiders or visitors aiming at creating a welfare and development supporting local community survival. Defined in 1971 in France ecomuseum refers to a new idea of holistic interpretation of cultural heritage with a focus on regional identity.

A definition from the European network of Ecomuseums from 2004 states that an Ecomuseum is a dynamic way in which communities preserve, interpret, and manage their heritage for a sustainable development. An Ecomuseum is based on a community agreement.

\section{What can be the role of architects in such regional contexts?}

An inspiration can be found in the work of Samuel Mockbee and his Rural studio [4] established in 1993 at Alabama in USA. Rural Studio is an undergraduate program of the School of Architecture, Planning and Landscape Architecture at Auburn University. It is an off-campus design-build program where students assist some underserved population in the region while developing an ethos of recycling, reusing and remaking.

"Theory and practice are not only interwoven with one's culture but with the responsibility of shaping the environment, of breaking up social complacency, and challenging the power of the status quo." Sambo Mockbee

According to Mockbee everyone regardless of his/her social-economic status deserves to live within decently designed buildings and he intentionally brought students to some physically poor settlements where they were helping residents designing and building houses and other buildings. Thus students had the opportunity to have a hand-on educational experience and be involved in a community participation type of design. The Studio continually questions what should be built, rather than what can be built, both for the performance and operation of the projects.
Students are looking for practical solutions of real community problems and besides design they are involved in fund-raising and construction of their architectural projects. In this way they grow up as "citizen architects" being aware of the social and environmental responsibility each architect should carry nowadays and at the same time they experience the sense of satisfaction when seeing the positive impact their work can bring into real human and community life.

The film "Citizen Architect" offers a strong insight into the philosophy and educational methods of Sambo Mockbee and Rural studio program where students are approaching architectural education as an applied cultural anthropology trying to make a design which can communicate at the level of community values and lifestyle.

I believe that in order to develop fruitful communication and exchange with local community students should establish and continuously reconsider their own design philosophy. For this purpose the phenomenological approach of Yuhani Pallasmaa [5] can be very useful. In phenomenology, the environment is concretely defined as "the place", and the things which occur there "take place". "The place" can be related to the Japanese fudo or the human milieau, because it consists of "things" with certain sensual characteristics forming "an atmosphere" which allows certain spaces, with similar or even identical functions, to embody very different properties. The atmosphere is in the middle of the relationship between society and its environment resembling the mediance of Berque. In this context atmosphere, fudo and milieau function as synonyms.

Following this approach we should first dig into our own experience of material substance, shape, texture, and color of the built environment of the visited place of study trying to record into a kind of ethnographic diary all the features which we find as forming the atmosphere of the place.

The distinction between natural and manmade offers us the first step in the phenomenological approach. The second is to qualify inside and outside, or the relationship of earth-sky. The third and final step is to assess character, or how things are made and exist as participants in their environment. Only after this preliminary research we are ready to communicate with local people on the atmosphere of the place thus bringing our understanding into a comparative perspective.

Architectural phenomenologist Juhani Pallasmaa posited a series of questions facing the architecture profession: "Can architecture define a credible social and cultural goal for itself? Can architecture be rooted in culture in order to create an experience of locality, place, and identity?"

$\mathrm{He}$ has defined six themes in architecture 
which are going to be important to reflect for the next millennium- slowness, plasticity, sensuousness, authenticity, idealization, silence.

Slowness is the counterpoint of the obsession with speed and novelty pushed to be the measure of our world perception by media. "Architecture requires slowness in order to develop again a cumulative knowledge, to accumulate a sense of continuity, and to become enrooted in culture" (Pallasmaa, Encounters I, 2012, p.301) [5].

Slowness relates to the necessity of architecture to address and communicate at a protoarchaic level of human psyche and its bio-cultural dimensions. It reminds me the relationship between regional architecture and fudo or milieau of the social texture amidst the natural environment. For me it is the metamorphosis of genius loci into genius societatis of each particular place and its community.

The issue of plasticity refers to the weakening of the physical reality of architecture and its inherent connection with the language of the body. "With the loss of tactility, and the measures and details crafted for the human body and hand, architecture becomes repulsively flat, sharp-edged, immaterial, and unreal." (Pallasmaa, Encounters I, 2012, p.302) [5]. As examples of plasticity in architecture Pallasmaa gives the buildings of the Erechtheion in Acropolis and the Ronchamp Chapel of Le Corbusier.

The issue of sensuousness relates to the gap between our sensory experience of the world and the bio-cultural responses in our unconsciousness. "The rainfall of images" defined by Italo Calvino transforms architecture predominantly into an art of the eye. "Architecture's task is to provide the stable and reliable ground for the perception of the world, for the ground of homecoming into the world" (Ibid, p.302) [5]. Architecture of good quality relates to "embodied images of an authentic life, with all its contradictions and irreconcilabilities".

Pallasmaa defines authenticity as "the quality of deep rootedness in the stratifications of culture". Architecture should defend the autonomy of emotional response. As examples Pallasmaa gives Villa Mairea by Alvar Alto as a work deeply rooted in the stratifications of culture and the Oval Shaker box as a work unconditioned by consumerism. The authenticity is the pathway "to dwell with dignity" (Ibid, p.304) [5].

Idealization for Pallasmaa is related to the belief that architecture should reify an ideal view of life. Each architect should have a vision and aspire toward an ideal- otherwise there is no architecture.

He continues further that the masterpieces of Modern architecture such as Maison de Verre in Paris by Pierre Chareau or Kidosaki house by Tadao Ando present idealized possibilities of human existence. Architecture should tolerate and encourage individualization by seeking a relationship to images rooted in our common memory- "the phenomenologically authentic ground of architecture".

For Pallasmaa empathy and humility should be key words for architecture in the next millennium.

As the sixth theme Pallasmaa writes about silence as an independent sensory and mental state that evokes a sense of melancholy and a yearning for an absent ideal. The person who perceives architecture of silence finds him/herself listening to his/her own being. Great works of architecture petrify silence as its timeless monuments.

For me the buildings designed by Fumihiko Maki illustrate mastering of all the six themes in architecture as defined by Pallasmaa.

Fumihiko Maki entitles his lecture in Sofia in 2012 'Quiet Architecture' [6] and in an interview taken by architect Georgi Stanishev and me he recommended to observe the silence of the spaces created by him. In 2009 he has designed The University of Pennsylvania Annenberg Public Policy Center, USA (Fig. 1, 2, 4) taking into a deep consideration the inner comfort of the researchers by using mainly natural wood in the interior spaces. Visiting the Center a year after its completion he was delighted to hear the researchers telling him that they go to their working place with pleasure and the results of their research has been improved.

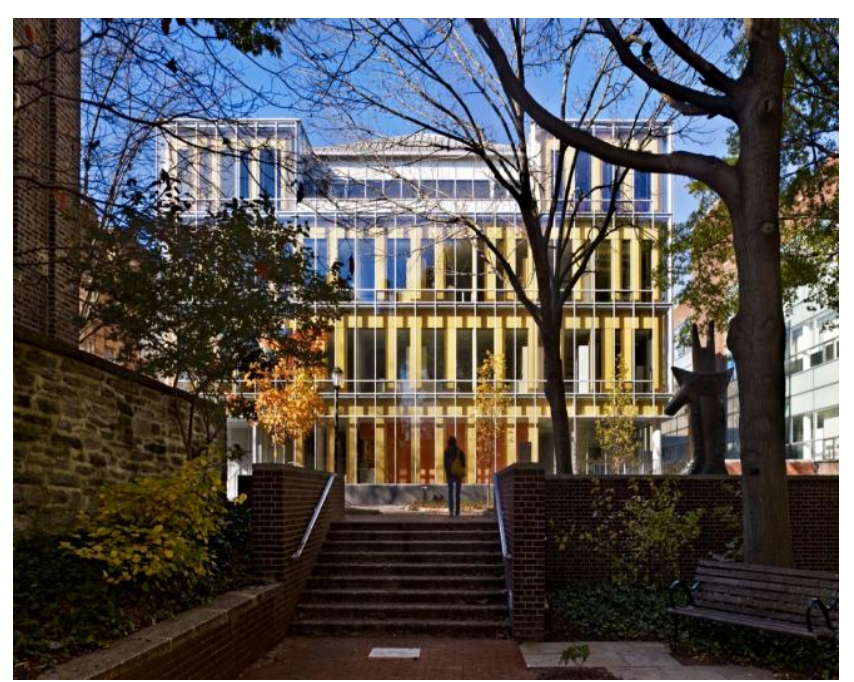

Figure 1: Fumihiko Maki, The University of Pennsylvania Annenberg Public Policy Center, USA photo-courtesy of Fumihiko Maki

Maki has designed Aga Khan Museum in Ontario, Canada (Fig.3). The concept of the design is to create an ever-changing canvas for the display of light. In this regard, the building has been envisioned as a kind of precious stone, which can exhibit reflectivity, color variations, translucency, and a visual mystery.

The quiet architecture of Maki addresses all six themes defined by Pallasmaa as important for the new millennium. It addresses the issue of slowness as 
Maki takes care of the buildings he designed long time beyond their completion. He constantly revisits his buildings and takes care of any emergent problems during exploitation. Thus architecture for him is a longlife attending of his creations.

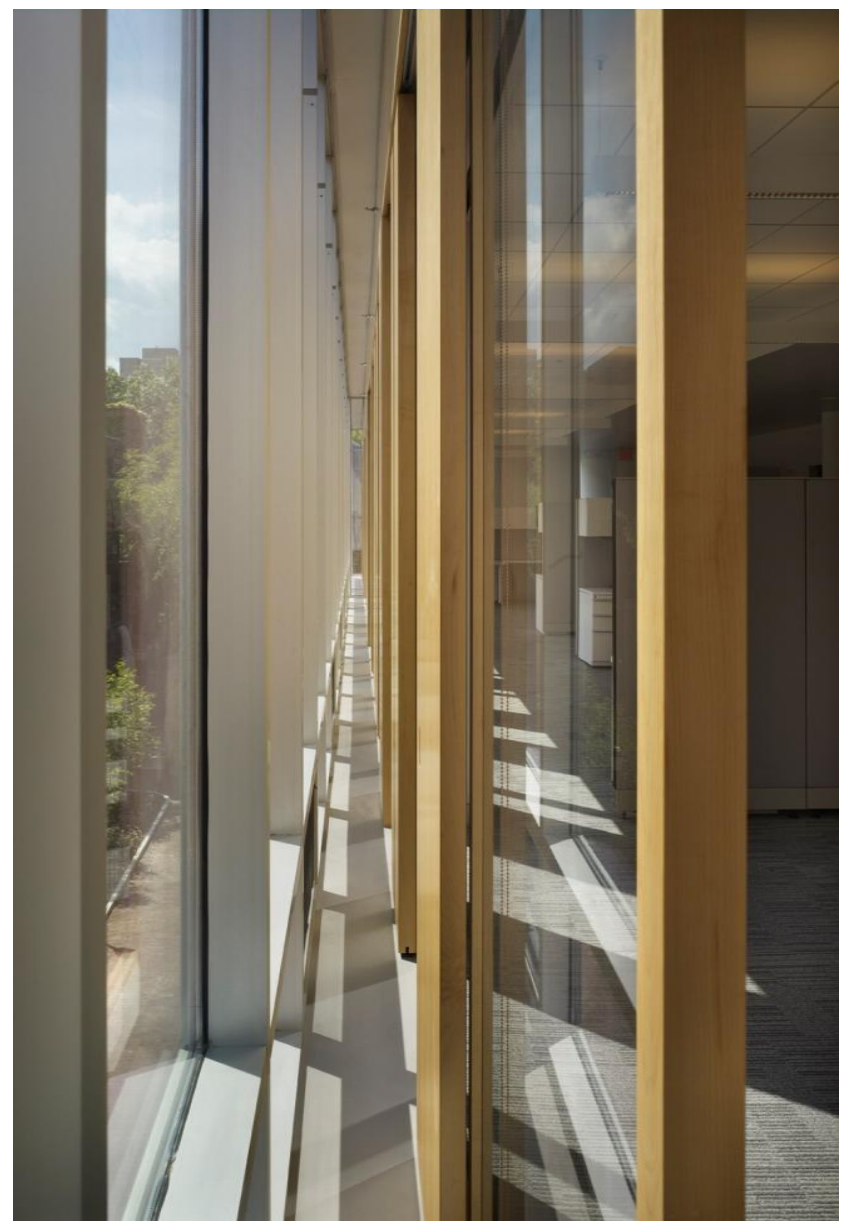

Figure 2: Fumihiko Maki, the University of Pennsylvania Annenberg Public Policy Center, USA

His architecture addresses sensuousness and plasticity as he is aiming to create a pleasurable sensuous experience for the visitors of his buildings being aware that to enjoy the space with all senses is a primordial aspect of perception not only of humans but also of animals.

His architecture is authentic, being deeply rooted in his sensitivity as a Japanese and the rationality of his strong academic background in architecture in Japan and USA. Being one of the founders of metabolism in Japan, he contributes to the leading position of Japanese architect in contemporary architecture, while keeping an individualistic professional attitude and a self-centrism within group projects. As an example of this attitude I can give the design of Roppongi Hills compound where Maki was in charge to design Asahi TV headquarters building and he didn't disclose his architectural intentions almost to the end of the design stage of this megaproject.

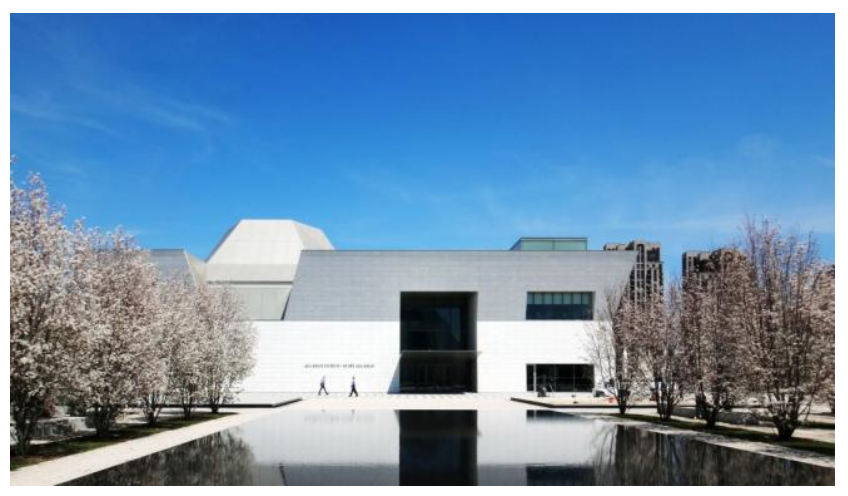

Figure 3: Fumihiko Maki, Aga Khan Museum in Ontario, Canadaphoto-courtesy of Fumihiko Maki

Maki architecture is always based on idealization in the sense that he is aiming to improve the quality of life of the users of his buildings [7, 8]. Example of this attitude is the design of the Spiral building in Tokyo where he designed free of charge and consummation seating places, facing the street where Tokyoites can enjoy a view over Tokyo cityscape and perceive its urban vitality.

Visiting Kaze-no-Oka Crematorium he designed in a small scale settlement Nakatsu in Oita prefecture, Maki was pleased to hear the comments of the residents that they feel relaxed to die with dignity after he designed such a spiritual place.

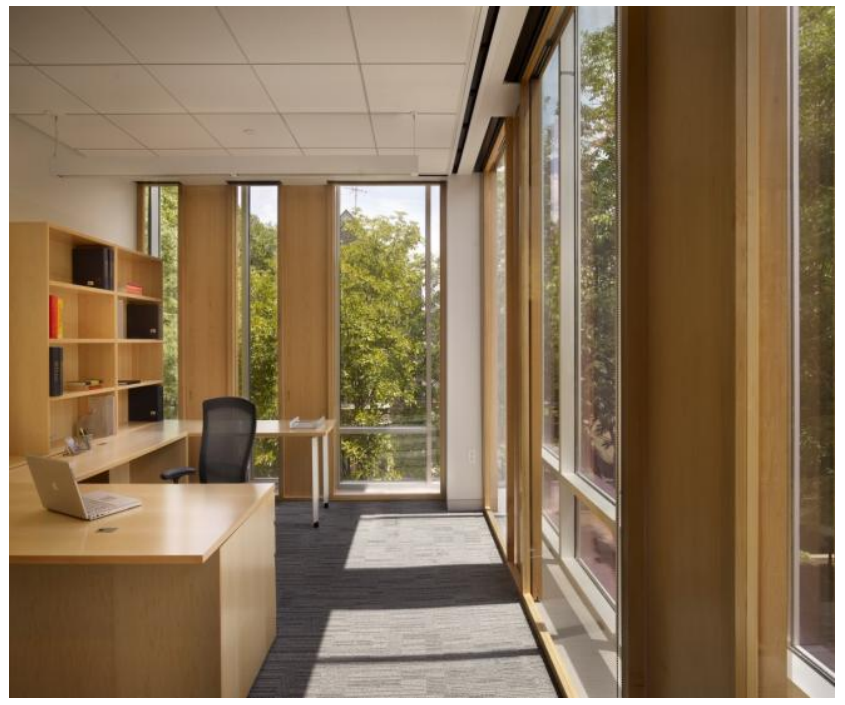

Figure 4: Fumihiko Maki, the University of Pennsylvania Annenberg Public Policy Center, USA photo-courtesy of Fumihiko Maki

\section{Micro-design intervention as a strategy}

Based on the phenomenological approach of the architects and scholars mentioned above I have formulated a framework of a micro-design intervention for the practical training of students in the department 
of architecture as a fieldwork research and design during their summer practices.

\section{Study the milieau or fudo}

1. Immersion in the local mileau

2. Observe the climatic features, natural topography, flora, fauna and available materials for architecture. Create an outsider perspective of the potential of the place.

3. Communicate with local people getting to know their attitude to the above mentioned elements. Formulate an insider perspective of the place.

\section{Object of design intervention}

1. Make considerations of certain spatial problems or conflicts you observe between the lifestyle of people and the features of their spatial environment.

2. Listen to the needs of local people and what are their expectations. Try to have as deeper understanding as possible of their way of life and value scale.

3. Define an object of design intervention answering both your own considerations about fudo and local people cosmological views.

\section{Design \& Make}

1. Make preliminary design sketches and try to define your concept on the base of best fit within the peculiar fudo of the place

2. Communicate your ideas to local people and try to reach an emotional resonance - people should be able to relate and identify with your idea as reaching their own value scale.

3. Measure your idea according to Pallasmaa points- slowness, plasticity, sensuousness, authenticity, idealization, silence.

4. Make technical design drawings.

5. Realize your project.

By following these steps I believe students will develop an authentic environmental design consciousness which would enable them to be better prepared for the actual dynamic professional reality. Only by being sensitive to fudo, respecting local people views and cosmology, at the same time have the bravery to defend an independent design philosophy within their micro-design interventions, it is possible to achieve a socially and environmentally sustainable design in harmony with the regional cultural context.

If they learn how to relate their ideas to various kind of people or in other words to be polyglots in mastering various languages of communication besides the graphic expression of architects, students can reach the enlightenment of authentic architecture.

As the best examples of such architecture I consider the project of Renzo Piano for a cultural center for the Kanak culture in the New Caledonia, where he worked on site together with an anthropologist in order to reach the point when local people could easily identify with his ingenious design.

\section{Two fieldworks in 2014}

I would like to give two examples from fieldworks held with students of architecture in the summer of 2014.

The first one happened in the village of Kovachevitza in South-western Bulgaria in the mountain of Rodopi (Fig. 5). This village was declared an architectural reserve and its houses are made of stone and wood with a particular design of the wooden joints specific for this area.

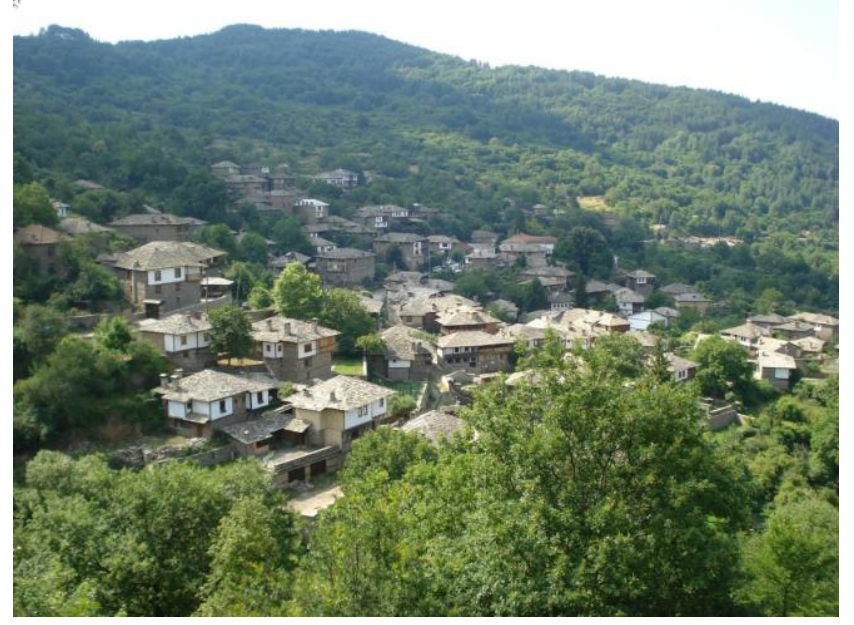

Figure 5: A panorama of the village of Kovachevitza- photo by Lilyan Delevski

Students went on site and the first days were observing various features of the landscape, townscape and lifestyle of people. On the base of their observations they decided to activate a space at the edge of the village in the village entry by constructing a bench where people could sit and have a talk (Fig. $6)$.

After the bench was made, they could see how people immediately started to use it as it was always there and this was the best proof that their micro-design intervention was successful. 


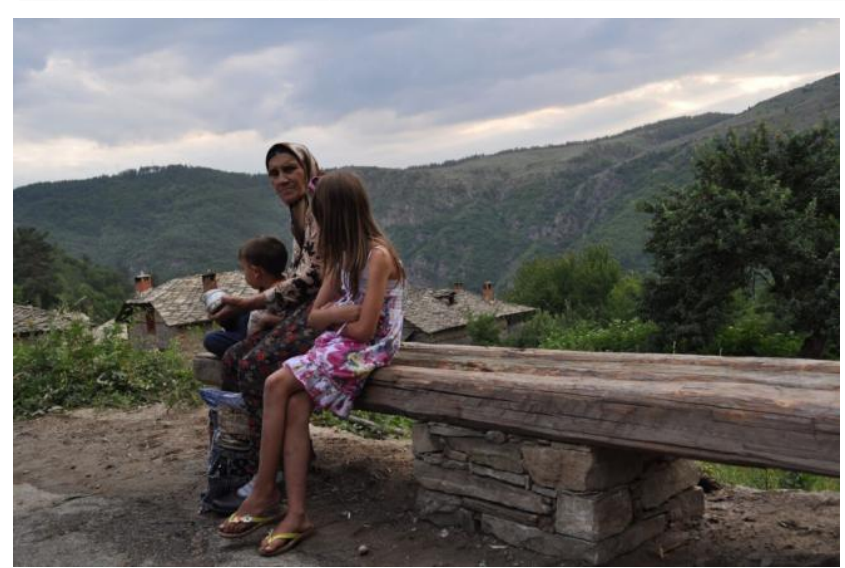

Figure 6: The bench at the edge of the village of Kovachevitzaphoto by Projektirane

The following year they have selected the other edge at end of the village as a place of their intervention and have constructed a viewing platform for the visitors and locals (Fig. 7, 8). A short video of the working process is available at the following site https://www.youtube.com/watch?v=6_dJjtnYsuQ [9].

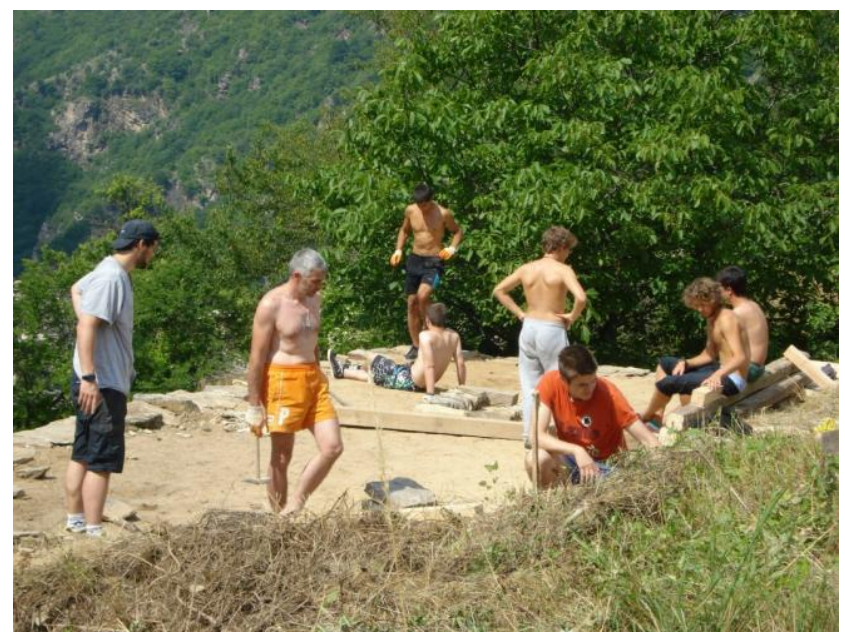

Figure 7: At the place of the viewing platformbefore intervention- photo by Projektirane

The second example is from the village of Karpachevo, which is located at the Devetaki Plateau - a natural reserve near the towns of Lovech and Troyan at the Balkan mountain.

Thanks to the enthusiasm of the British conservation architect Darren Barker and a grant from a British Preservation Trust a project to study and conserve an historic mill was launched in 2013. The building of the mill is made of a special kind of travertine called bigor, which was widely used for various purposes in the past, but now it is forbidden to use this stone for constructions due to its scarcity.

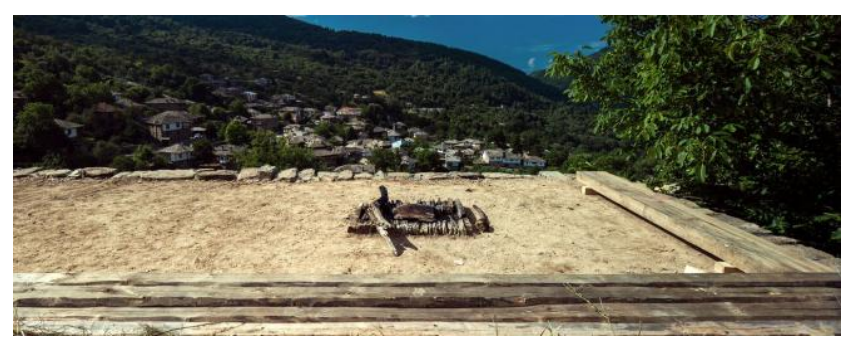

Figure 8: At the place of the viewing platform-after interventionphoto by Projektirane

A group of students and teachers went to Karpachevo to research the architecture of the mill which is abandoned and try to find an appropriate way to adapt it for new functions. After library research and interviews with local people, we found an old photo of the mill, proving the fact that originally it was built in the neighbouring village of Krushuna as a water mill on a river at the beginning of $20^{\text {th }}$ century and in 1930's was bought, dismantled and reconstructed as an electric mill in the village of Karpachevo. Students made a detailed analysis of the features of the existing building and try to decode all the transformations within the history of the building. Detailed measurements were taken and the actual situation of the building was fully documented.

In communication with the head of local NGO for the revitalization of Devetaki Plateau, students try to design proposals for an adaptive reuse of the building, trying to preserve as much as possible the authentic wooden skeleton, the travertine walls, the window and door design and the spatial structure of the interior space. After discussions it was accepted the concept of a Local Culture Mill- a tourist visitor centre with a small exhibition and a place for backpackers. In the past the mill used to prepare food for household animals, which were the livelihood of the village. Nowadays the region is heavily depopulating and the strategy to develop sustainable tourism focuses on the local natural and cultural specifics of all nine villages on the Devetaki Plateau.

Students decided to stimulate eco-museum type of regional endogeneous development in which the mill located at the entrance to the plateau would serve as a cultural gateway to the region.

In conclusion, nowadays human consciousness of being interdependent on the climate and environmental features of our planet is getting stronger each day. The visible changes of the geography of our volcanoes, the poles and the cities facing water basins inevitably poses the question how to bear a strong responsibility of human interventions during the speedy economic development and increasing consumer needs. It is obvious that architects should be educated in the spirit of the environmental consequences and the impact of their buildings on natural and human habitat. 
Based on the research of Toshio Mitsuhashi, Yuhani Pallasmaa and Augustine Berque and the practice of Rural studio, Fumihiko Maki and Renzo Piano I have tried to define a framework for a microdesign intervention as a strategy to achieve socially and environmentally sustainable architectural design. This framework is appropriate to be taught to students of architecture in order to stimulate the development of a strong environmental design consciousness which should be a priority in the contemporary architectural education. In my view the best way to achieve this, is to bring students for longer periods of fieldworks in the countryside where they can have a repetitive exposure to natural and human relationship or fudo of the place. Only by an immersion and physical experience of the lifestyle of the place they could grasp genius loci and genius societatis to enable them to create meaningful architectural interventions.

A student shared with me that the fieldwork in Karpachevo has changed his general attitude to architecture and his ambitions. To be aware of architecture as a way to exist, communicating with others within nature and creating spatial interventions as a fruit, born out of these human contacts amidst natural settings, seems to me to be the relevant way how to educate architectural students.

In this sense micro-design intervention can be a kind of social acupuncture, which presses some neuralgic points within human settlements in order to release the blocked energy of social and natural relationships.

These practical experiences seek to transform the research theory of sustainable environmental design into a pragmatic strategy to strengthen environmental consciousness for young generations in Bulgaria. Working and living together in rural or mountain traditional environments, trying to understand and assist local people by creating microdesign interventions is one of the best ways to heighten environmental design consciousness by an immersion in the milieau of local culture and community relationships. A socially sustainable microdesign intervention is only possible by combining the tools of an anthropologist and a designer or in other words by finding the intersection and cross-fertilization points between the cultural values of insiders and observers.

\section{References}

1. Mitsuhashi T, Miyazaki K. Some Aspects of an Endogeneous Regional Development. Bulletin of Japanese Society for Science of Design, 2003.

2. Watsuji T. Climate and Culture: A Philosophical Study. The Hokuseido Press, 1971.

3. Berque A. Thinking through Landscape. Routledge, 2013.
4. Documentary film "Citizen Architect", Samuel Mockbee and Rural studio, 2013.

5. Pallasmaa J. Encounters 1 - Architectural Essays. Rakennustieto Publishing, Estonia, 2012.

6. Maki F. Quiet architecture. Presentation at the UACEG, Sofia during the 13th Architectural triennale Interarch, 2012.

7. Maki F. Toward the Construction of Place from recent works. Presentation at UACEG, Sofia during the 14th Architectural triennale Interarch, 2015.

8. Maki F. An Aesthetic of Fragmentation. Rizzoli International Publications, New York, 1988.

9. https://www.youtube.com/watch?v=6_dJjtnYsuQ 